UCRL-ID-131690

$\vdots$

\title{
Analysis of Market Penetration Scenarios of Clean Coal Technologies in China using the LLNL China Energy Model
}

Alan Lamont

August 17, 1998

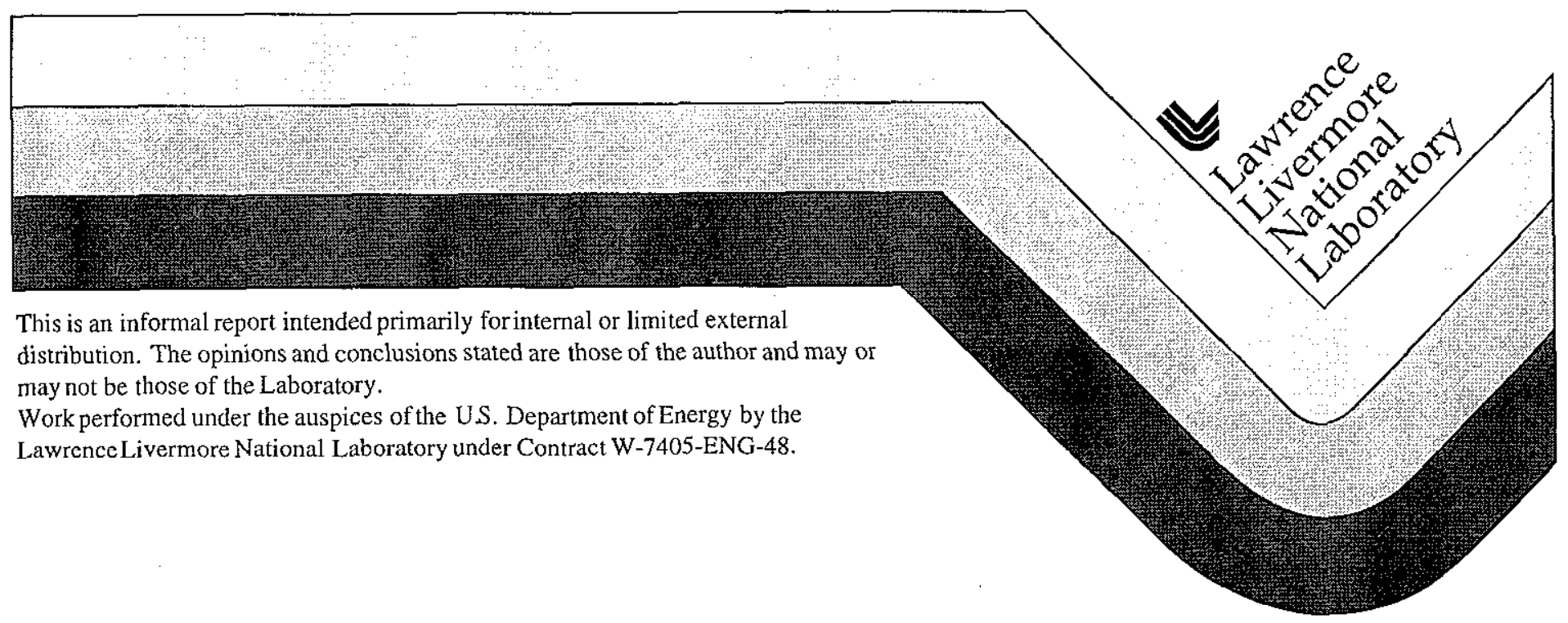




\section{DISCLAIMER}

This document was prepared as an account of work sponsored by an agency of the United States Government. Neither the United States Government nor the University of California nor any of their employees, makes any warranty, express or implied, or assumes any legal liability or responsibility for the accuracy, completeness, or usefulness of any information, apparatus, product, or process disclosed, or represents that its use would not infringe privately owned rights. Reference herein to any specific commercial product, process, or service by trade name, trademark, manufacturer, or otherwise, does not necessarily constitute or imply its endorsement, recommendation, or favoring by the United States Government or the University of California. The views and opinions of authors expressed herein do not necessarily state or reflect those of the United States Government or the University of California, and shall not be used for advertising or product endorsement purposes.

This report has been reproduced directly from the best available copy.

Available to DOE and DOE contractors from the Office of Scientific and Technical Information

P.O. Box 62, Oak Ridge, TN 37831

Prices available from (615) 576-8401, FTS 626-8401

Available to the public from the

National Technical Information Service

U.S. Department of Commerce

5285 Port Royal Rd.,

Springfield, VA 22161 


\title{
Analysis of Market Penetration Scenarios of Clean Coal Technologies in China using the LLNL China Energy Model
}

\author{
Alan Lamont \\ Lamont1@llnl.gov \\ Lawrence Livermore National Laboratory \\ Livermore, California, USA
}

\section{Abstract}

This paper presents the results of an analysis of the market penetration of Clean Coal Technologies in the electric utility market in China. The analysis is based on a model of the Chinese energy system developed at Lawrence Livermore National Laboratory. Under this model, the market penetration of a technology depends on the relative prices of all technologies in a market. The model assumes that for each technology there is a distribution of effective prices to the consumers in the market place. The prices for each technology computed in the model are assumed to be the means of these distributions: sometime the effective price is greater than this and sometimes it is less. Thus even a relatively expensive technology may cost less than its competitors in a fraction of the transactions. Using several scenarios about the possible dispersion of prices, we estimate the market share of CCTs over the next 50 years. We find that some CCTs penetrate under all scenarios, but the more expensive ones only show significant penetration when larger values of price dispersion are assumed. Generally the penetration of the CCTs is $15 \%$ or less of the market by 2020 . However, advanced pulverized coal does exceed $15 \%$ in some cases.

\section{Introduction}

The energy system in China relies heavily on coal for both heating and electric generation. Within the electric sector, a large portion of the installed capacity is of relatively older design with lower efficiencies and higher emissions than more modern technologies. A number of "clean coal technologies" (CCT) have been developed which have both high efficiencies and relatively low emissions of sulfur and particulates. Introducing these CCTs to the Chinese market could reduce emissions of carbon, sulfur and particulates. However, it is not clear to what extent they might penetrate the market and reduce emissions.

This paper reports the results of a study of CCT market penetration that was done using the China Energy Model developed at the Lawrence Livermore National Laboratory (LLNL). The model accounts for market penetration based on the relative prices of competing technologies. However, 
the market model recognizes that there is a variability of prices within a market. This variability contributes to market penetration of a technology even if it is more expensive than its competitors on the average.

The section below first discuss the modeling approach. Then we discuss the scope and structure of the model of the Chinese energy system. Next we address the issue of cost variability, primarily to demonstrate the extent of cost variability and to identify two scenarios of cost variability for analysis. Finally we run the model under two scenarios of cost variability to estimate the impacts on market penetration and the overall reduction in environmental impacts that could be achieved using CCTs.

\section{Modeling approach}

This model is developed using the META $\bullet$ Net modeling system developed at LLNL (Lamont). Under this approach, an economic system is represented as a network of interconnected nodes. The nodes represent economic processes such as end-use demand, conversion technologies, resources, and markets. The links pass information about quantities demanded and prices. Figure 1 shows a simple network for illustration.

META - Net is a modeling system that allows the user to build models based on this representation. It includes a library of node types and allows the user to build a model by simply specifying the nodes and their links. This approach has the advantage that it is easy to build and modify models. The node models can also be readily extended to model additional types of economic behavior.

The model is typically set up to compute a price quantity equilibrium over multiple period-the China model uses ten five-year periods. Over the model horizon, the model computes price trajectories, quantities, addition and retirement of capital stocks, and exhaustion of resources.

\section{Computation of prices, quantities and economic equilibrium}

To solve the model, we compute a price-quantity equilibrium through a sequence of iterations passing quantities demanded down from the end-use nodes and prices up from the resource nodes. At the start of an iteration, demands are generated at the end-use nodes. These are passed down the network. At market nodes the total market demand is allocated to the suppliers based on their relative prices (this is discussed in greater depth later). The conversion node represent fixed coefficient production processes. Based on the input-output coefficients, they compute the quantity of each input that that are required to produce the output required of them.

The quantities demanded eventually reach the resource nodes. At this point, the model begins to compute prices and send them back up through the network. Resource nodes contain resource curves that provide the marginal price required to produce the quantity demanded as a function of 
the total resource that has been exploited up to that period. The conversion nodes receive the prices for each input. Based on the prices of inputs, their I-O coefficients, capital costs, operating costs, and unit availability, the conversion nodes compute the price required in order that the owner of the process will receive a target rate of return on capital investments. The market nodes compute a quantity weighted average price for the market based and pass that on up. When the prices are received by the end-use nodes, a new quantity demanded is computed using a demand curve. These quantities are passed down to start a new iteration.

Figure 1: Simple illustrative model network

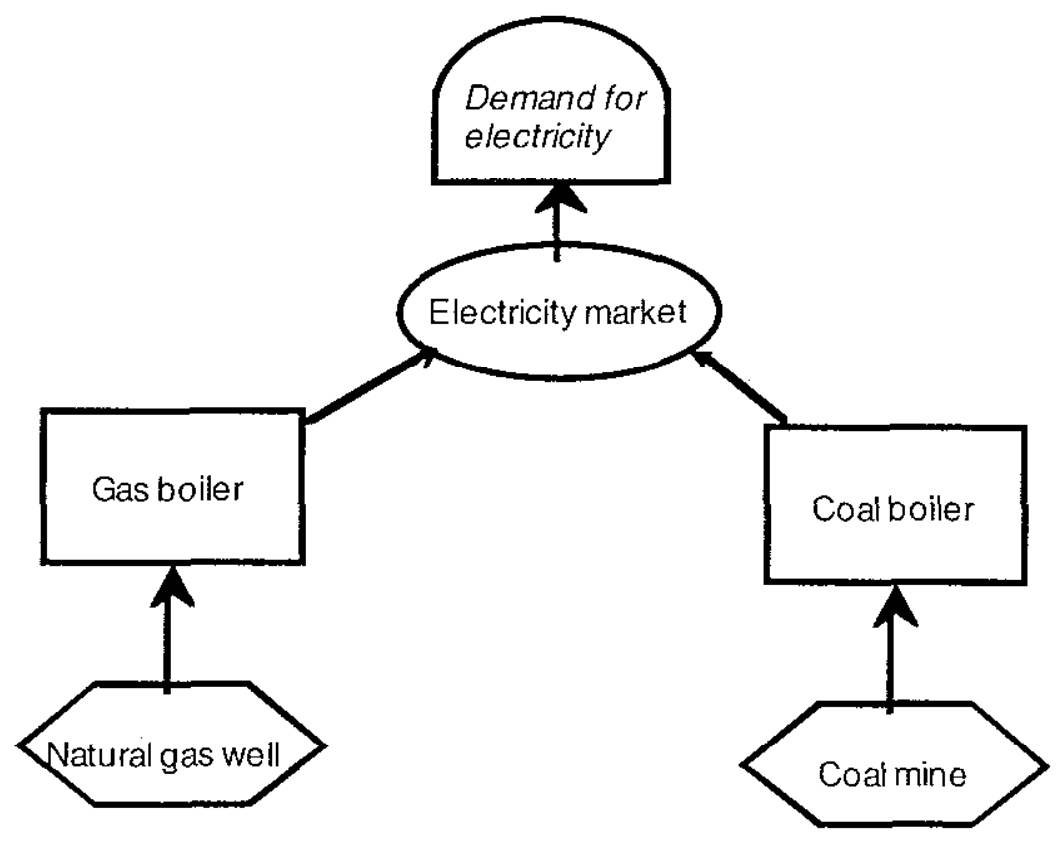

\section{Market nodes}

The market nodes compute the allocation of market demand to the market's suppliers based on their prices. Under this approach, the lowest price supplier does not receive the entire demand. Rather he receives a fraction of the demand based on the difference between his price and the prices of other suppliers. Such allocations are frequently done using a logistic function. However, in this case we use somewhat different approach developed by Boyd, et al.

This approach notes that the price on a single supply link to a market in the model actually represents a range of prices. These suppliers will typically have a distribution of costs (or prices that they must charge) and the price they actually charge may vary from instance to instance. Further, there can be a range of other costs that will change the effective price to a buyer. These might include transportation costs not represented in the model or 
other financing costs. The price for a supply link computed by the model represents the average price of all the suppliers on that link. Given that there is a distribution of prices, there will be instances when purchasing from a supplier on Link $A$ is less expensive than purchasing from suppliers on Link $B$, even if, on the average, the suppliers on Link A are more expensive.

Based on this approach, the fraction of the market that suppliers on link A receive is computed as the fraction of instances where it is cheaper than the suppliers on another link. Heuristically, we can say that the more the two price distributions overlap, the more equal the market shares will be. When there are just two supply links to a market, we can write the equation for the fraction of the market going to supplier $A$ as:

Fract $_{\mathrm{A}}=\int_{0}^{\infty} f_{A}\left(p_{A}\right) \bullet F_{B}\left(p_{A}\right) \cdot d p_{A}$

where

$f_{A}\left(p_{A}\right)=$ The probability density distribution over the effective prices for suppliers on link A

$F_{B}\left(p_{A}\right)=$ The probability that the effective prices for all suppliers on link $B$ will be greater than $p_{A}$.

If we assume that the distribution of prices follows a Weibull distribution, then there is a simple equation for market share based on the average prices and a single parameter called the "market price sensitivity parameter". The larger the value of the parameter the more sensitive the market is to prices. That is in a very sensitive market, a supplier with a price just slightly higher than a competitor will receive a small market share. This occurs since a large value of price sensitivity implies a very narrow distribution of prices. Thus there are very few instances where the price distributions overlap. The market price sensitivity parameter is a direct function of the coefficient of variation (COV) ${ }^{1}$ of the price distributions.

The market share curves produced by this approach are similar in shape to those produced by a logistic market share function. However, using this formulation we can relate the market price sensitivity parameter directly to assumptions about the variability of prices in the market. In the sections below we will assume different values of the coefficient of variation to explore its impact on the results.

\section{Relationship to optimization models}

There is a close relationship between economic equilibrium and cost minimization. A META $\bullet$ Net model can be set up to approximate a cost

The coefficient of variation (COV) of a probability distribution is defined as (standard deviation)/mean 
minimization solution. If the market nodes are set to be highly sensitive, they will allocate the demands to suppliers so as to approximately equalize their marginal costs. This minimizes the total cost of meeting the demand in the market. Overall this procedure will approximately minimize the total cost of meeting the demands.

\section{Constraints}

Both quantity and price constraints can be added to any of the links in the model. These operate by raising the prices sent to market nodes to ensure that the allocations meet the constraints. Based on the results from a model run, the shadow prices of the constraints can be estimated

\section{Scope and Structure of the China energy system model}

The model of the Chinese energy system has been developed to explore the impact of new technologies in an energy system such as China's.

The structure of the model is shown in Figure 2 The end-use sectors include Industrial, agricultural, commercial, residential (divided into urban and rural) and transportation. The energy supply sectors include: petroleum (imported and domestic), natural gas (imported and domestic), coal, and biomass. Wind, hydro, and nuclear resources are also included. The electric sector includes generation by domestic technology coal boilers (with and without flue gas desulfurization), foreign technology pulverized coal, atmospheric fluidized bed, integrated gasification and combined cycle, Oil fired combined cycle, hydro, wind and nuclear.

The industrial sector has been further divided into older and more modern technologies. In future studies we expect to investigate the impact of introducing newer, more efficient industrial technologies. In the present study, we have assumed that the industrial technologies have the efficiency of current technologies.

\section{Data sources}

Most of the data on energy flows and capacities is derived from the China Energy Databook, published by Lawrence Berkeley National Laboratory (LBNL) and other publications or memos from LBNL. Estimates of costs of electric generating technologies are based in part on data provided by the US Department of Energy, Office of Fossil Energy (Atwood) and by LBNL. These data attempted to reflect the actual costs that would be incurred in China. Other estimates of operating costs and characteristics are based on information from the Technology Assessment Guide (TAG) published by the Electric Power Research Institute. However, the costs in the TAG are for construction and operation in the US. Adjustments were made to attempt to reflect the actual costs found in China. Data about other elements of the energy system were adjusted from data about the US energy system compiled at Lawrence Livermore National Laboratory 
The model is run for ten five year periods nominally starting in 1990 . The quantities and prices predicted by the model for the period 1990-95 were compared to the data in the China Energy Data Book. We find reasonably close agreement (after some adjustments) in computed prices, quantity flows, and installed capacity in the electric sector.

\section{Constraints on rate of technology capacity development}

Since several of the technologies are not currently widespread in China, it is likely that their rate of introduction would be constrained since it takes time to develop the skills and infrastructure needed to construct and operate a new technology. In this model it is assumed that the CCTs could increase by $10 \%$ per year. As can be seen in the results below, this constraint is binding in the early periods and the installed capacity is at the constraint. Eventually each technology finds a stable level of market penetration and tends to remain at that value.

It is also assumed that the rate at which hydro power could be developed is limited. It is assumed here that the amount of hydroelectric power available would increase steadily from about $130 \mathrm{TWh} / \mathrm{yr}$ in 1990 to about 1,000 TWh/yr at the end of the model horizon in 2035. The cost of hydropower is assumed to be low enough that the permitted amount of capacity would always be developed.

\section{Assumptions about technology costs and cost variability}

Assumptions about the variability of costs is one of the basic inputs to the market share model. We could expect the cost of a given type of generator to vary from installation to installation due to factors such as local skills and experience, skills and experience of the company building the facility, variations in cost of cooling or transmission, and variations in the attractiveness of financing and other costs that must be negotiated for each installation.

\section{Scenarios of cost variability}

To develop some perspective on the range of variability that might be possible, we have used data compiled by Sinton (Sinton, 1995) on observed power plant capital costs in the past few years in China. The data should be viewed with some caution: They come from several sources and it is not clear that the same accounting conventions were used to compute capital costs. The data also refer to a range of plant sizes. A few are small (less than $100 \mathrm{MW}$ ) but the rest are in the range of several hundred MW. The data are presented as a histogram in Figure 3.

There are two outliers with very high costs that apparently include transmission and distribution costs. For the remaining cases, the coefficient of variation in costs is 0.36 . 


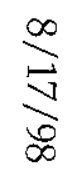

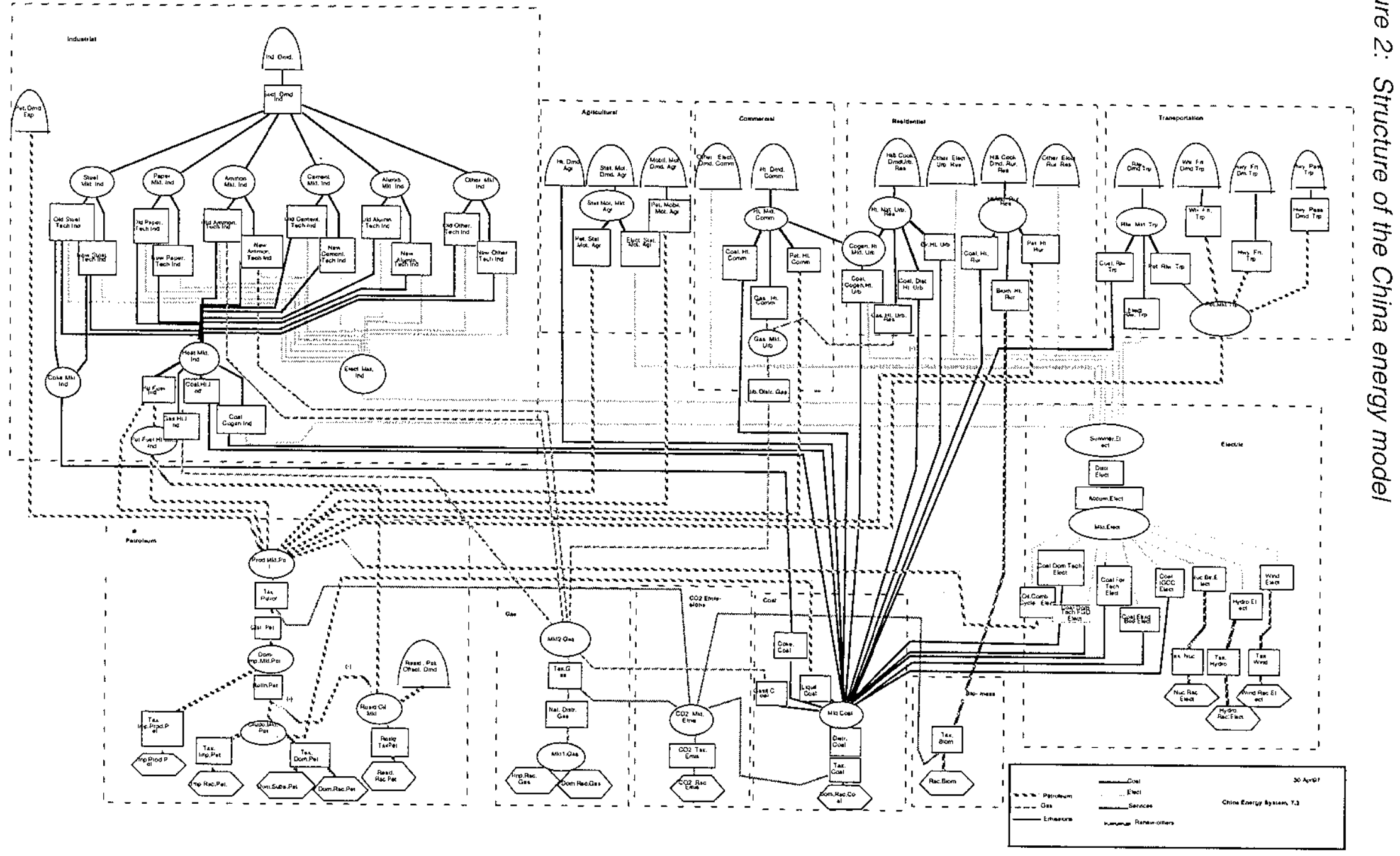


Figure 3: Variability in capital costs for coal fired power plants in China

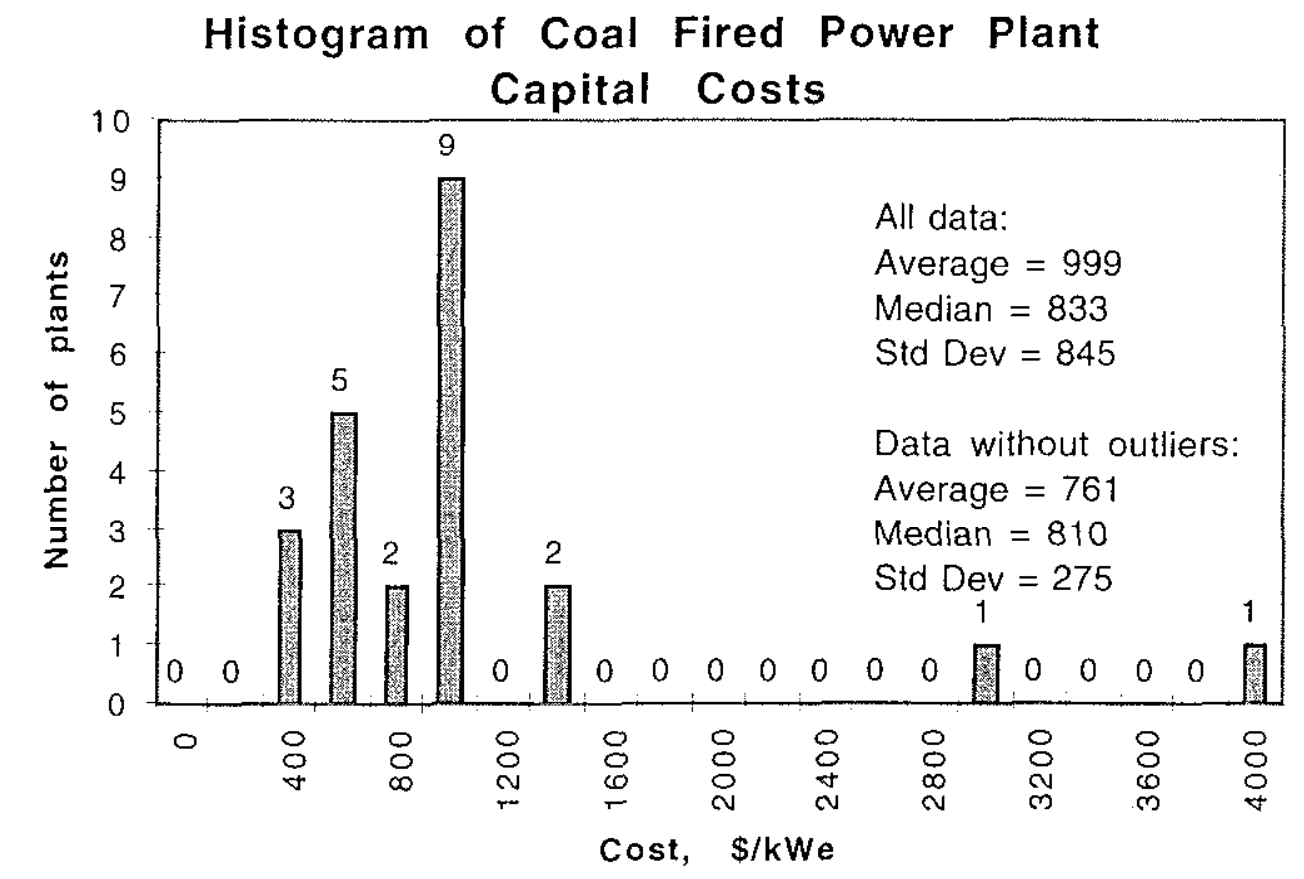

From Sinton, J "A Review of Power Plant Costs in China", LBNL, 1995

For the purpose of this analysis we have chosen three scenarios on price variability in the electric market. The first scenario assumes very little variability. The coefficient of variation is set at 0.04 (i.e. the standard deviation of the price distribution is assumed to be $4 \%$ of the average price). This represents something close to what optimization models might do. For the upper bound case we will use a value of 0.25 . It seems plausible that there could be at least this much variation in the costs within China. As an intermediate case we will assume a COV of 0.10.

The assumption of higher COVs will tend to increase the penetration of more expensive technologies at the expense of less expensive technologies. Taken to the extreme, a very large COV will result in each supplier link to a market receiving about the same share of the market, regardless of their relative prices.

\section{Costs of electric generators}

The costs assumed for electric generators in this study are shown in Table 1 . These inputs were assembled and adapted from a variety of sources discussed above. 
Table 1: Assumed costs for electric generating technologies

\begin{tabular}{|c|c|c|c|c|c|c|}
\hline Cost inputs & $\begin{array}{ll}\text { Domestic } \\
\text { Tech }\end{array}$ & $\begin{array}{l}\text { Domestic } \\
\text { Tech } \\
\text { FGD }\end{array}$ & $\begin{array}{l}\text { Foreign } \\
\text { Tech., } \\
\text { Pulv. } \\
\text { Coal }\end{array}$ & $\begin{array}{l}\text { Fluidized } \\
\text { Bed }\end{array}$ & $\begin{array}{l}\text { Integrated } \\
\text { Gasif- } \\
\text { ication } \\
\text { Combined } \\
\text { Cycle }\end{array}$ & $\begin{array}{l}\text { Oil Fired } \\
\text { Combined } \\
\text { Cycle }\end{array}$ \\
\hline Interest rate & 0.1 & 0.1 & 0.1 & 0.1 & 0.1 & 0.1 \\
\hline Capital cost, $\$ / \mathrm{kwe}$ & 600 & 680 & 780 & 800 & 850 & 500 \\
\hline Life, yrs. & 30 & 30 & 30 & 30 & 30 & 30 \\
\hline $\begin{array}{l}\text { Variable operating cost, } \\
\$ / \mathrm{kWh}\end{array}$ & 0.0013 & 0.0014 & 0.0013 & 0.0017 & 0.0019 & 0.0017 \\
\hline $\begin{array}{l}\text { Fixed operating cost, } \\
\$ / \mathrm{kW} \text {-yr }\end{array}$ & 13.2 & 15 & 13.1 & 17.25 & 19.4 & 1.9 \\
\hline $\begin{array}{l}\text { Consumables cost, } \\
\$ / \mathrm{kWh}\end{array}$ & 0.00065 & 0.00135 & 0.00065 & 0.00215 & 0.0002 & 0.0002 \\
\hline Efficiency & 0.33 & 0.27 & 0.38 & 0.39 & 0.42 & 0.50 \\
\hline Availability factor & 0.70 & 0.70 & 0.85 & 0.81 & 0.85 & 0.91 \\
\hline
\end{tabular}

\section{Implications of scenarios on cost variability for clean coal technology market penetration and environmental impacts}

The market penetrations for the various technologies are shown in Figure 4, Figure 5, and Figure 6 in terms of share of installed capacity. The domestic coal technology is relatively inexpensive and holds a larger market share than the other coal technologies. As would be expected, its market share declines as we assume a larger COV, since a large COV implies that there are more opportunities for the other technologies to win market share.

The foreign pulverized coal technology is close to the cost of domestic technology (actually, in these runs it is slightly less expensive, 223 vs 227 $\mathrm{Y} / \mathrm{MWh}$ in base load mode). Its market share tends to increase as quickly as the constraint on its introduction allows. In all cases, it reaches around a 10\% or more market share by 2020 .

The integrated gasification and combined cycle technology also captures market share. However, it reaches it maximum share of between $9 \%$ and $11 \%$ at around year 2020. Its market share does not increase appreciably after that time in any of the cases.

Coal fluidized bed is the most sensitive to assumptions about the COV of prices. At a COV of 0.4 it essentially does not gain market share. While at a COV of 0.25 , it reaches about a $10 \%$ market share. 
Figure 4: Market shares of electric generation technologies assuming COV of 0.04

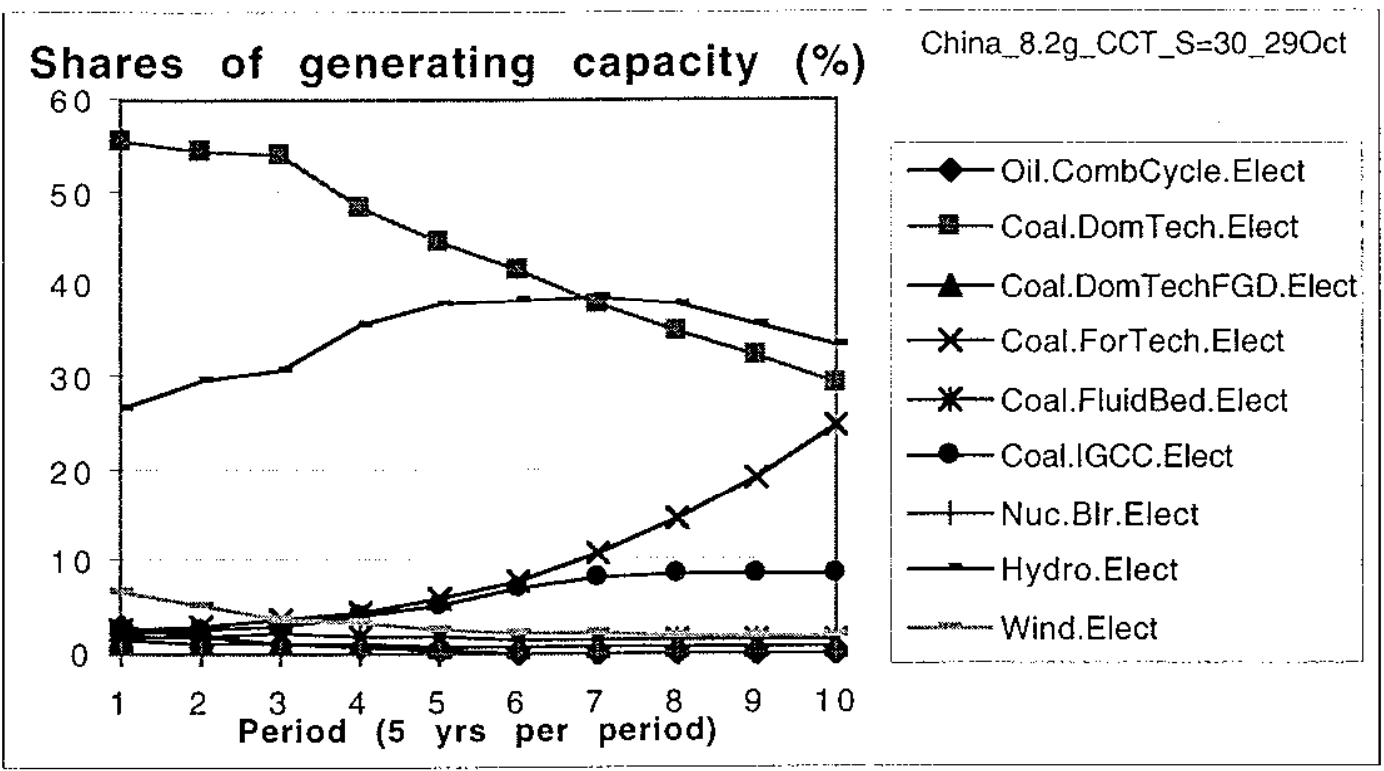

Figure 5: Market shares of electric generation technologies assuming COV of 0.10

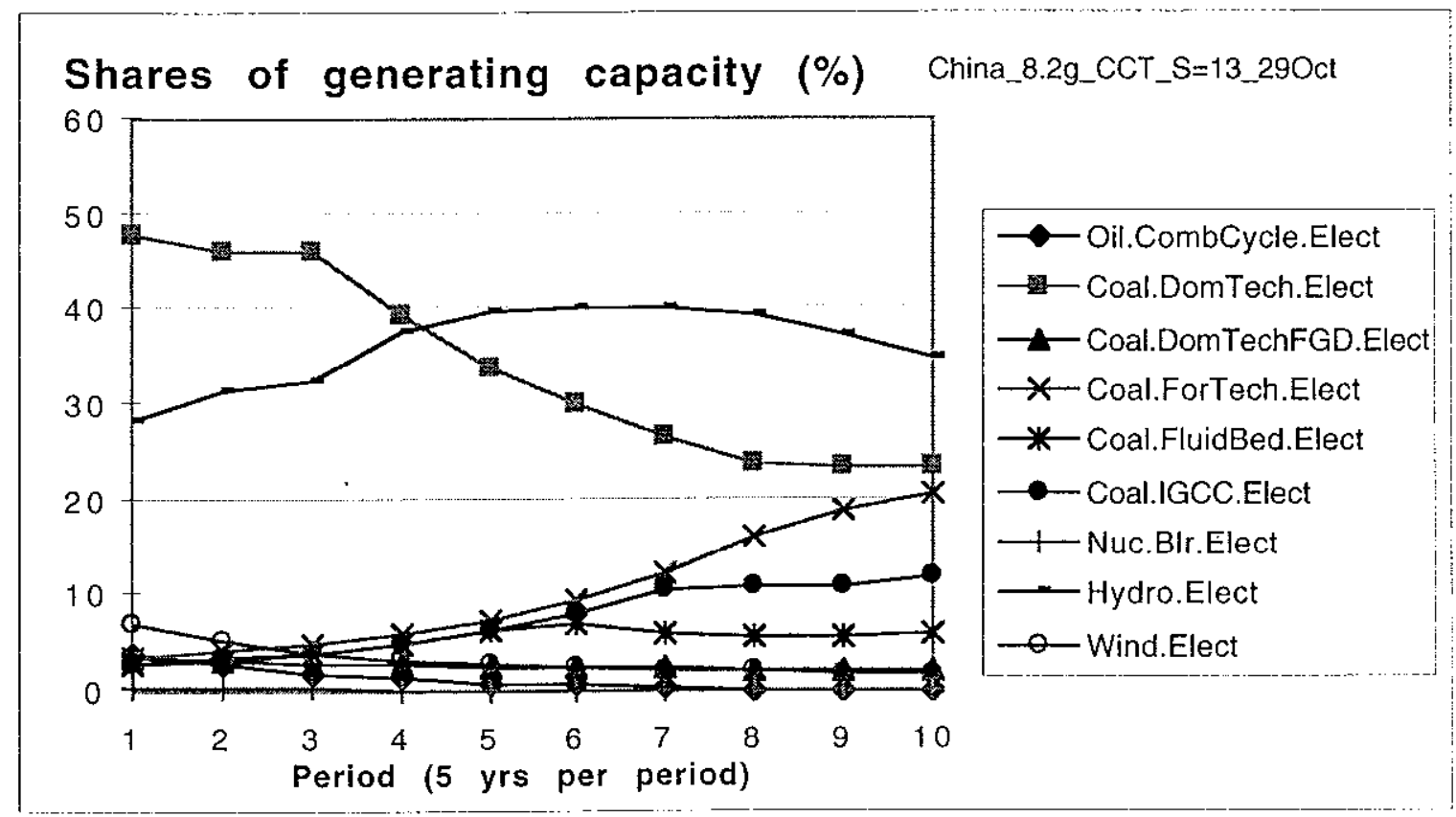


the case where no CCTs are allowed into the market, and for the three market penetration scenarios analyzed here. The sulfur emissions estimates are based on the assumption that Chinese steam coal averages $1.1 \%$ sulfur (Sinton, China Energy Data Book).

\section{Conclusions}

These results indicate that assumptions about market conditions have a strong effect on market penetration forecasts, particularly for more expensive technologies. If there is very little variation in prices, and markets are optimizing on prices, the penetration of more expensive technologies (such as fluidized bed in this study), will show little penetration. However, plausible assumption about market conditions lead to the result that there will be a significant market penetration, even by the more expensive technologies.

However, we also find that the penetration of the more expensive technologies is limited, even under the more optimistic market assumptions. The market share tends to increase as quickly as capacity can be constructed up to a point, around the year 2020 in these runs. After that the market share stabilizes at levels ranging from a few percent to $15 \%$ depending on the scenario and the technology.

Figure 7: Sulfur emissions from electric utility sector for base case with no CCTs introduced and for several scenarios of market penetration of CCTS

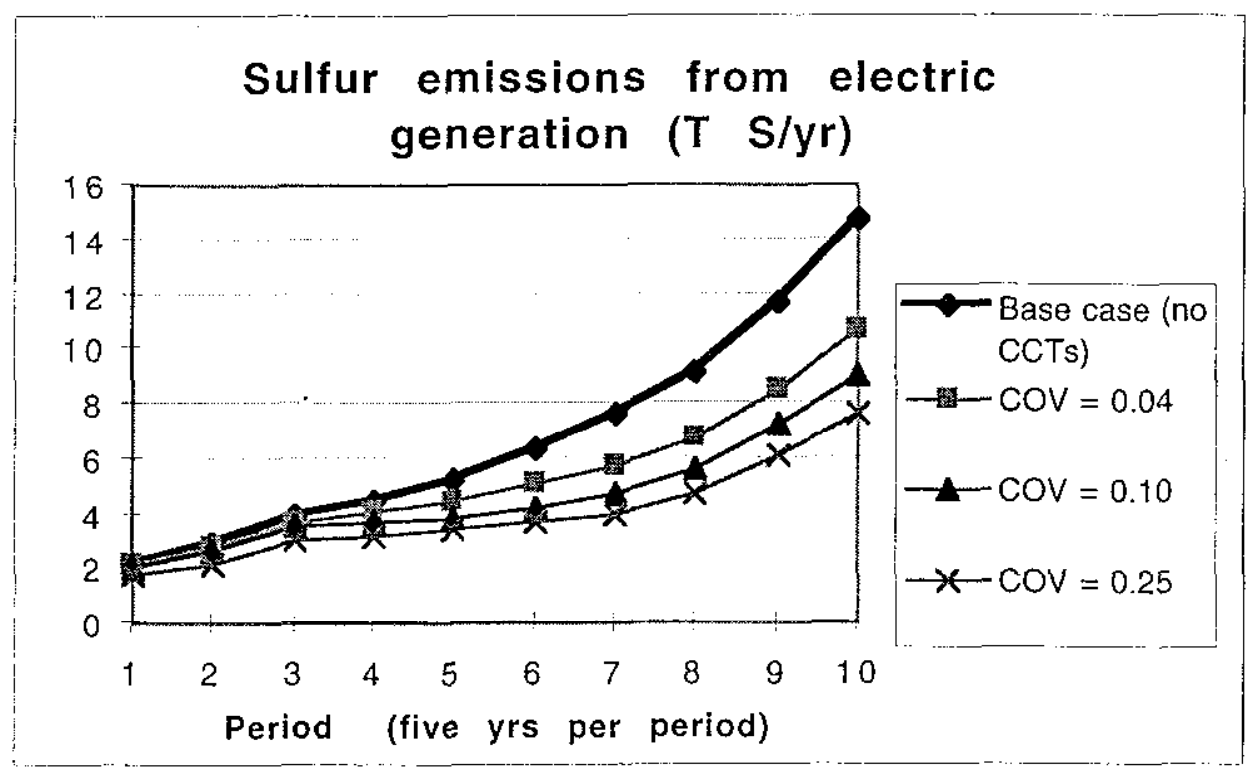




\section{References}

Atwood, $\mathrm{T}$ Data on cost capital cost estimates and efficiencies for various generating technologies, personal communication. US DOE Office of Fossil Energy

Boyd, D., R. Phillips, and S. Regulinski "A Model of Technology Selection by Cost Minimizing Producers, Management Science, Vol. 28, No. 4, April 1982

Electric Power Research Institute Technology Assessment Guide, EPRI P6587-L, Vol. 1: Rev. 6, September 1989

Lamont, A. User's Guide to the META $\bullet$ Net Economic Modeling System Lawrence Livermore National Laboratory, UCRL-ID-122511, November, 1994

Sinton, J. (ed.) China Energy Databook, Lawrence Berkeley National Laboratory, LBL-32822 Rev. 4, UC-900, September 1996

Sinton, J. A Review of Power Plant Costs in China, Lawrence Berkeley National Laboratory, Energy Analysis Division, unpublished memo, December 1995 